\title{
Pemikiran dan Peradaban Islam di Masa Rasulullah SAW
}

\author{
Sofiah Rosyadi
}

Email: najmaimrani@gmail.com

\section{A. Latar Belakang}

Kehidupan Rasulullah adalah sejarah yang perlu kita kaji dan dalami sebagai umat Islam. Sungguh Allah telah memberikan kelebihan pada kita dijadikannya sebagai umat Islam, umatnya nabi Muhammad SAW. Nabi Muhammad SAW adalah nabi yang berbudi pekerti luhur yang luar biasa dalam memulai adanya peradaban Islam sejak ditugaskan nya beliau menjadi nabi dan rasul di umur beliau ke-40 tahun sungguh luar biasa hasil yang diraih oleh Nabi Muhammad dalam menjunjung agama Islam di peradaban dan pemikirannya menjadikan peradaban Islam adalah peradaban yang berpengaruh yang mana Rasulullah adalah paling sempurna makhluk ciptaan Allah yang membawa rahmat untuk seluruh alam

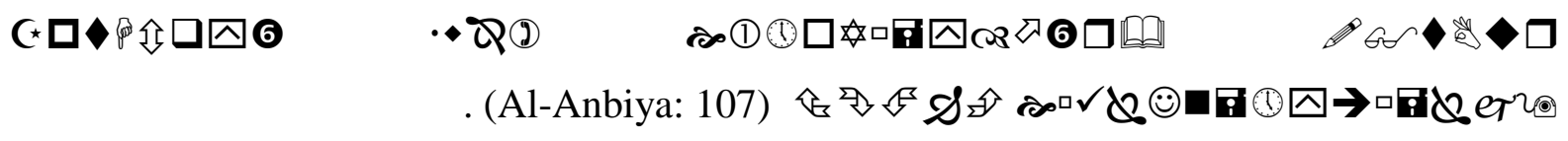

dan didukung terdapatnya dalam diri beliau dari akhlak yang mulia sebagaimana firman Allah SWT

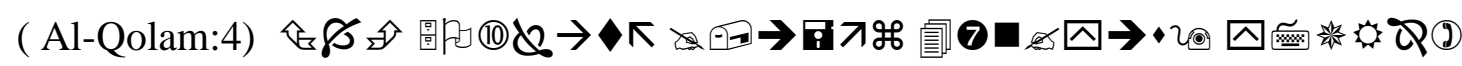

Pembahasan pada makalah ini kita akan mengetahui lagi dan kehidupan Rasulullah dalam membawa agama Allah yakni Islam, sebagai agama yang membawa peradaban dan pemikiran yang menjadi sejarah penting dalam Islam yang membuat Islam pada masa itu sebagai awal peradaban menjadikan masyarakat Arab yang bersuku-suku yang menganggap perbuatannya turun-temurun itu benar menjadi bangsa yang tentram dan dinamis. Dalam makalah ini saya akan melaporkan sejarah singkat Nabi Muhammad dari awal muncul kelahirannya sama yang mana sampai pada turunnya wahyu yang menjadikan pelantikan nabi 
dan rasul kepada Nabi Muhammad SAW disusul dengan perjalanan dakwah Rasulullah terbagi ke dalam dua periode, yaitu periode Mekkah dan periode Madinah. Periode Mekkah. berlangsung lebih kurang 13 tahun dan periode Madinah 10 tahun.

\section{PEMBAHASAN}

\section{A. Nabi Muhammad SAW dan Diangkatnya Menjadi Nabi \& Rasul}

Beliau adalah Muhammad ibn Abdillah ibn Abdul Muthallibibn Hasyim ibn 'Abdu Manaf ibn Qushayy ibn Kilab ibnMurrah ibn Ka'b ibn Lu'ay ibn Ghalib ibn Fihr ibn Malik ibnal-Nadhar ibn Kinanah ibn Khuzaymah ibn Mudrikah ibn Ilyasibn Mudharr ibn Nazzar ibn Ma'add ibn Adnan ("Adnan adalah putra Nabi Isma'il). Inilah nasab yang disepakati sejarawan dan ulama ahli nasab.

Nabi dilahirkan pada Senin, 12 Rabiul Awal, Tahun Gajah;tahun ketika Abrahah alAsyram memerangi Makkah danmenghancurkan Ka'bah tapi gagal. Abrahah dan pasukannya dihancurkan Allah dan dijadikan sebagai tanda kekuasaan-Nya bagi umat manusia sebagaimana terangkum dalam surah Al-Fil. kelahiran Nabi, menurut sebagian ulama, bertepatan dengan bulan April tahun $571 \mathrm{M}$.

Beliau dilahirkan yatim di rumah Abu Tholib dari Bani Hasyim. Ayah beliau, Abdullah bin Abdul Muthalib meninggal dunia saat beliau baru berumur 2 bulan dalam kandungan sang ibu Aminah binti Wahab dan stelah lahir disusui seorang perempuan dari bani Sa'ad bin Abu Bakar bernama Halimah binti Abi Dzu'aiyb Abdillah bin Al Harits ${ }^{1}$.

Disaat usia 6 tahun Beliau wafatlah ibunya Aminah, kemudian ia berpindah diasuh oleh kakeknya, Abdul Muthalib, sampai pada masa wafat kakeknya yang mana pada saat itu Beliau genap berumur 8 tahun, dan selanjutnya pamannya yang mengurus, Abu Thalib yang tersohor dengan karismatiknya di kalangan kaum Quraish ${ }^{2}$.

Masa kecil Muhammad diisi dengan menggembalakan domba orang-orang Quraisy. Hal itu ia lakukan untuk membantu perekonomian pamannya. Meskipun niat mulianya ini

\footnotetext{
${ }^{1}$ Qasim A Ibrahim , Muhammad A Saleh, Buku Pintar Sejarah Islam Jejak Langkah Peradaban Islam Dari Masa Nabi Hingga Masa Kini (Zaman, 2014)hal.22

2 Muhammad Sa'eed Ramadhan Albuthi, Figh al Siirah Muhammad SAW (Beirut-Lebanon: Dar El Fikr, 1993).hal.38
} 
padaawalnya ditentang keras oleh paman dan bibinya, namun dengan tekad dan alasan yang kuat akhirnya Abu Thalib mengizinkan keinginan Muhammad tersebut. Di sela-sela menggembalakan hewan ternak ini, Muhammad banyak merenung dan berpikir. Suatu tindakan yang tidak lazim dilakukan oleh seorang anak kecil. Namun demikian, proses ini kemudian menjadikan Muhammad berbeda dengan anak-anak kecil Arab lainnya. Salah satu perbedaan itu yang kemudian dikenal luas oleh masyarakat Mekkah ketika itu adalah kejujuran yang sangat menonjol pada diri Muhammad. Dikarenakan kejujuran itu kemudian dia diberi gelar Al-Amin, orang yang terpercaya. Gelar ini selanjutnya sangat mendukung proses dakwah Muhammad dikemudian hari. Selain itu, pada masa kecilnya Muhammad nampak berbeda bila dibandingkan dengan anak-anak kecil lainnya karena ia memiliki sifatsifat layaknya orang dewasa. Pada saat Muhammad diasuh oleh Abu Thalib kondisi kehidupan pamannya itu sangat sederhana. Dengan anak yang banyak Abu Thalib harus menambah beban hidupnya dengan mengasuh keponakannya. Tidak jarang pada saat mau makan anak-anak Abu Thalib berebut makanan karena takut tidak kebagian. Hal yang berbeda dilakukan oleh Muhammad. Ia sama sekali tidak mau berebut makanan. Muhammad rela menunggu apa yang ia dapatkan dan mendapatkan makanan apa adanya. Melihat hal itu istri Abu Thalib, Fatimah bint Asad, kemudian selalu menyisakan makanan untuk Muhammad sehingga setiap akan makan ia tidak perlu menunggu karena makanan telah disisakan oleh istri Abu Thalib. Hal inilah yang kemudian menyebabkan anak-anak Abu Thalib menilai ibunya lebih sayang kepada Muhammad dibandingkan kepada mereka ${ }^{3}$.

Mulai usia 12 tahun, beliau telah menemani pamannya berdagang ke Syam. Tetapi di tengah perjalanan bertemu dengan seorang Rahib Nasrani yang bernama Bahira. Kemudian ia melarang Abu Thalib membiarkan Muhammad tanpa pengawalan, sebab ia melihat tanda kenabian dalam diri Muhammad, dan jika tanda itu diketahui oleh orang Yahudi dikawatirkan mereka akan membunuhnya.

Di usia yang ke 25 tahun, Beliau menikah dengan seorang janda kaya dan cantik, Khadijah. Hal ini terjadi atas ketertarikan Khadijah terhadap Muhammad yang jujur dan cakap ${ }^{4}$.Di saat umur 25 tahun itu Beliau semakin giat terjun ke dunia dagang sampai pada saat membawa dagangan dengan modal milik Khadijah bint Khuwaylid ke Syam ditemani budak Khadijah yang bernama Maysarah, setelah pulang dari berdagang di Syam yang setelahnya membawa Khadijah meminta pertolongan Nafisah bint Muniyyah untuk menikahi

\footnotetext{
${ }^{3}$ Kartika Sari dan M Hum, "SEJARAH PERADABAN ISLAM," Shiddiq Press, 2015, 144.hal.19

${ }^{4}$ Zakki Fu'ad, Sejarah Peradaban Islam Paradigma Teks, Reflektif, dan Filosofis, t.t., hal.10.
} 
Muhammad. Nabi Muhammad tidak pernah menikah lagi hingga Khadijah wafat . Dari pernikahan inilah lahir semua anak beliau, kecuali Ibrahim yang merupakan hasil pernikahannya dengan Mariyah al-Qibtiyyah ${ }^{5}$.

Ada kejadian penting yaitu pembangunan Ka'bah dan pemutusan perkaraoleh Nabi tatkala Nabi berumur 35 tahun, suku Quraisy berencana mem-perbaiki bangunan Ka'bah setelah dihantam banjir hebat.Mereka merobohkan Ka'bah, lalu membaginya menjadi beberapa bagian. Tiap-tiap suku di sana diberi satu bagian untuk dibangun kembali. Saat tiba waktu peletakan Hajar Aswad,mereka berselisih tentang siapa yang paling berhak meletakkannya kembali di tempat semula. Mereka hampir saja salingbunuh jika Abu Umayyah alMughirah tak menawarkan satu usulan; orang yang paling berhak meletakkannya adalah yang paling awal masuk ke masjid. Atas kehendak Allah, keesokan harinya, ternyata orang tersebut adalah Nabi. Mereka pun setuju seraya berkata, "Kami rida bila al-amin yang melakukannya". Nabi kemudian membentangkan serbannya dan meletakkan Hajar Aswad di atasnya, lalu mengajak setiap pemimpin suku untukturut serta memegang setiap sudut serban dan mengangkatnyabersama-sama. Setelah mereka sampai di tempat Hajar Aswad,Nabi memegangnya sendiri dan meletakkannya ${ }^{6}$.

Menjelang usia 40 tahun, selama satu bulan dalam setiap tahun Muhammad mengasingkan diri ke Gua Hira' untuk merenungi alam dengan ciptaannya. Istrinya Khadijah memberi dukungan penuh terhadap keinginannya tersebut. Disediakannya makanan untuk dibawa suaminya Muhammad sebagai bekal ke Gua Hira’ itu.

Demikianlah dilakukan Muhammad setiap tahun. Ketika usianya 40 tahun, pada tanggal 17 Ramadhan $611 \mathrm{M}$, malaikat Jibril mendatanginya menyampaikan wahyu Allah yang pertama surat al-Alaq (ayat 1-5). Berarti secara simbolis Muhammad telah dilantik sebagai Nabi akhir zaman. Nabi Muhammad s.a.w. menceritakan peristiwa yang dialaminya itu kepada istrinya Khadijah. Rasulullah dibawa Khadijah menghadap seorang pendeta Nasrani yang berpengetahuan luas, bernama Waraqah bin Naufal. Setelah Nabi menceritakan pengalamannya itu, Waraqah berkata: "Inilah malaikat yang diturunkan Allah Swt. pada Nabi-nabi sebelummu..."

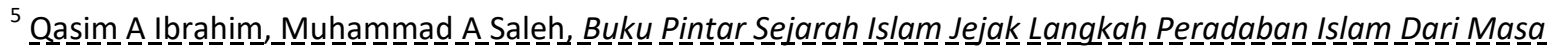
Nabi_ Hingga Masa_Kini_Zamana__2014L_ hal.24.

${ }^{6}$ Ibid,hal.25
} 
Setelah wahyu pertama itu datang, terputuslah wahyu selama lebih kurang dua tahun, kemudian Jibril datang lagi untuk membawa wahyu yang kedua, Surah al-Mudatsir (ayat 17). Dengan turunnya wahyu kedua itu, maka berarti Nabi sudah mulai wajib menyampaikan dakwah ${ }^{7}$.

Misi Rasulullah sebagai pembawa wahyu dari Allah mencakup misi duniawi dan akhirat. Artinya, Rasulullah bertugas menata masyarakat dari sisi moral dan bertugas merubah kondisi masyarakat Arab ketika itu. Dengan kata lain, Rasulullah membawa misi doktrin teologis dan doktrin teologis politis. Doktrin teologis artinya doktrin yang menekankan moralitas dalam mempersatukan ideal moral manusia dengan ideal moral Allah tanpa melakukan perubahan sosial politik. Adapun doktrin teologis politis menekankan moralitas sekaligus berusaha melakukan perubahan sistem sosial dan politik.

Dengan misi tersebut di atas maka sosok Nabi Muhammad dikenal sebagai seorang Nabi sekaligus sebagai negarawan. Ia adalah rasul pembawa ajaran Allah sekaligus negarawan yang memimpin umatnya. Nabi Muhammad bertugas memimpin umat Islam agar sukses di dunia dan di akhirat kelak. Dikarenakan misi besarnya itulah ia menjadi sosok yang dicontoh (suri tauladan) bagi umatnya.

Misi Nabi Muhammad yang termaktub dalam ajaran Islam berhasil membawa bangsa Arab yang sebelumnya barbar dan tidak dikenal oleh bangsa lainnya menjadi bangsa yang maju dan menguasai dunia. Beliau berhasil merubah kehidupan bangsa Arab dari berbagai sisi dan keadaan. Inilah yang membuat Nabi menjadi sosok yang dikenal sebagai sosok agung dan besar dalam dalam sejarah manusia ${ }^{8}$.

\footnotetext{
${ }^{7}$ Syamruddin Nasution, Sejarah Peradaban Islam (Pekan Baru - Riau: Yayasan Pustaka Riau, 2013), hal.34.

${ }^{8}$ Sari dan Hum, "SEJARAH PERADABAN ISLAM," hal.24.
} 


\section{A. Peradaban dan Pemikiran Islam di Mekkah}

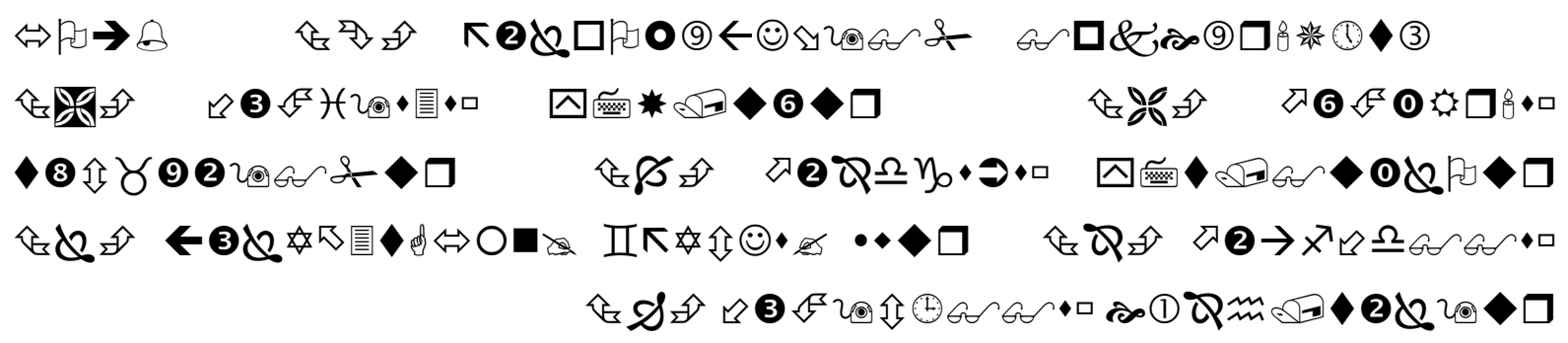

1. Hai orang yang berkemul (berselimut). 2. bangunlah, lalu berilah peringatan!. 3. dan Tuhanmu agungkanlah!. 4. dan pakaianmu bersihkanlah,5. dan perbuatan dosa tinggalkanlah,6. dan janganlah kamu memberi (dengan maksud) memperoleh (balasan) yang lebih banyak.7. dan untuk (memenuhi perintah) Tuhanmu, bersabarlah.\{Al-Mudatsir:1-7\}

Setelah turunnya surah Al-Mudatsir ayat 1-7 ini maka dimulailah Rasulullah dalam melaksanakan risalah yang diperintahkan Allah. Adapun tahap-tahap dakwah yang dijalankan Rasulullah pada masa periode Mekkah ini terbagi dalam tiga tahapan, yaitu;

1. Dakwah secara Sirriyyah atau Sembunyi-sembunyi.

Permulaan dakwah keislaman secara diam-diam ini nabi memulai dakwahnya Dengan mengajak orang-orang terdekat yang ia kenal dan mereka pun mengenal beliau diantara mereka terdapat nama Khadijah binti khuwailid(istri Nabi), Ali bin Abi Thalib(sepupu Nabi), Zaid bin Haritsah (bekas budak Nabi), dan Abu Bakar As Siddiq. Nama terakhir adalah sahabat dekat nabi pedagang yang jujur dan ahli nasab terkemuka yang giat di bidang dakwah mereka yang masuk Islam lantaran dirinya adalah Utsman bin Affan Zubair bin awwam Abdurrahman bin auf Saad bin Abi waqqash dan talhah bin Ubaidillah golongan pertama yang juga masuk Islam adalah beberapa tokoh Quraisy laki-laki dan perempuan dan sejumlah Maula atau bekas budak dan beberapa perempuan ${ }^{9}$.

Yang mana dengan beberapa sahabat yang pertama masuk islam ini menjadikan semakin hari banyak sejumlah orang yang ikut memeluk agama Islam. Walaupun yang masuk islam juga ada dari kalangan orang yang kaya, tapi mayoritas kebanyakan mereka adalah dari orang-orang yang miskin, rakyat lemah dan jelata.

\footnotetext{
${ }^{9}$ Ibrahim dan Saleh, Buku Pintar Sejarah Islam Jejak Langkah Peradaban Islam Dari Masa Nabi Hingga Masa Kini, hal.27.
} 
Perjalanan dakwah Nabi secara sembunyi-sembunyi ini berlangsung selama $3 \operatorname{tahun}^{10}$.

Selama jangka waktu ini telah terbentuk sekelompok orang-orang mukmin yang senantiasa menguatkan hubungan persaudaraan dan saling bahu-membahu. Penyampaian dakwah terus dilakukan, hingga turun wahyu yang mengharuskan Rasulullah SAW menampakkan dakwah kepada kaumnya. Menjelaskan kebatilan mereka dan menyerang berhala-berhala sesembahan mereka $^{11}$.

2. Dakwah secara terang-terangan di tengah penduduk Mekkah.

Dakwah Nabi secara terang-terangan ini didasari wahyu yang turun dari perintah Allah SWT:

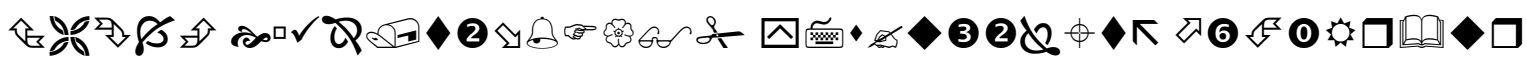

“Dan berilah peringatan kepada kerabat-kerabatmu yang terdekat”, $\{$ As-Syu'ara[26]:214\}

Pelaksanaan dari ayat ini Nabi mulai mendakwahkan islam di kalangan keluarga dan kerabatnya.

Langkah pertama yang dilakukan Rasulullah ialah dengan mengundang kerabat dekat beliau, seperti Bani Hasyim dan beberapa orang Bani Al-Muthalib bin Al-Manaf. Beliau menyeru kaumnya kepada Allah dan berserah diri kepada Rabb-Nya. Namun dari sekian banyak yang datang, semua menentang Rasulullah, hanya Abu Thalib-lah yang mendukung dan memerintahkan melanjutkan perjuangan Rasul. Setelah Nabi SAW merasa yakin terhadap dukungan dan janji Abu Thalib untuk melindunginya dalam menyampaikan wahyu Allah, maka suatu hari beliau berdiri di atas Shafa, lalu berseru: "Wahai semua orang!" maka semua orang berkumpul memenuhi seruan beliau, lalu beliau mengajak mereka kepada tauhid dan iman kepada risalah beliau serta iman kepada hari akhirat.

Dari yang hadir disitu, Abu Lahab angkat bicara : "Celakalah engkau untuk selamalamanya, untuk inikah engkau mengumpulkan kami." Lalu turun ayat: "Celakalah kedua tangan Abu Lahab"

Seruan beliau semakin menggema seantero Mekkah, hingga kemudian turun ayat:

\footnotetext{
${ }^{10}$ Albuthi, Fiqh al Siirah Muhammad SAW, hal.67.

${ }^{11}$ Siti Zubaidah, Sejarah Peradaban Islam (Perdana Mulya Sarana, 2016), hal.17.
} 


\section{色I

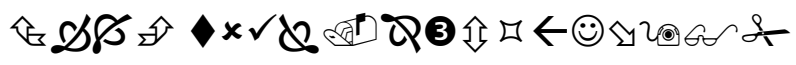

"Maka sampaikanlah olehmu secara terang-terangan segala apa yang diperintahkan (kepadamu) dan berpalinglah dari orang-orang yang musyrik". \{Al-Hijr[15]:94\}

Maka Rasulullah langsung bangkit menyerang berbagai khurafat dan kebohongan syirik dengan menyebutkan kedudukan berhala dan hakikatnya yang sama sekali tidak memiliki nilai. Mekkah berpijar dengan api kemarahan, bergolak dengan keanehan dan pengingkaran, tatkala mereka mendengar suara yang memperlihatkan kesesatan orang-orang musyrik dan para penyembah berhala. Suara itu seakan-akan petir yang membelah awan, berkilau, menggelegar dan mengguncang udara yang tadinya tenang. Orang-orang Quraisy bangkit untuk menghadang revolusi yang datang secara tak terduga ini, dan yang dikhawatirkan akan merusak tradisi warisan mereka.

Orang-orang Quraisy bingung, karena sepanjang sejarah nenek moyang mereka dan perjalanan kaumnya, mereka tidak pernah mengetahui bandingan yang seperti itu. Setelah menguras pikiran, tidak ada jalan lain lagi bagi mereka menghadapi orang yang jujur dan dapat dipercayai ini (Muhammad SAW) kecuali mendatangi paman beliau, Abu Thalib. Mereka meminta kepadanya agar menghentikan segala apa pun yang diperbuat anak saudaranya. Dengan perkataan yang halus dan lemah lembut, Abu Thalib menolak permintaan mereka. Maka mereka pun pulang dengan tangan hampa sehingga Rasulullah bisa melanjutkan dakwah, menampakkan agama Allah dan menyeru kepada-Nya. Semenjak penolakan itu, dan orang-orang Quraisy tahu bahwa Muhammad SAW sama sekali tidak menghentikan dakwahnya ${ }^{12}$.

Dakwah agama ini mulai dilancarkan nabi secara terbuka dan terang-terangan di setiap tempat di Mekah. ini juga menandai dimulainya tahap baru dakwah Islam yaitu tahap penyiksaan penghinaan dan pencerlaan oleh kaum musyrik terhadap orang Islam dan juga $\mathrm{Nabi}^{13}$.Ajakan secara terang-terangan ini dimulai dari sejak awal tahun keempat dari kenabian sampai akhir tahun kesepuluh ${ }^{14}$.

\footnotetext{
${ }^{12}$ Ibid, hal.19

${ }^{13}$ Ibrahim dan Saleh, Buku Pintar Sejarah Islam Jejak Langkah Peradaban Islam Dari Masa Nabi Hingga Masa Kini, hal.27.

${ }^{14}$ Zubaidah, Sejarah Peradaban Islam, hal.17.
} 
Orang-orang pemuka Quraisy dan orang-orang musyrik lainnya merasa terancam dalam kekuasaan, dikarenakan bertambahnya penduduk Mekah yang memeluk Islam,di sisi itu Nabi dan para pengikutnya semakin menancapkan perilaku yang simpati dan memiliki kepercayaan diri yang besar lagi berakhlak mulia yang menjadikan dorongan semakin bertambah banyak pengikutnya ${ }^{15}$.

\section{Dakwah diluar Mekkah.}

Karena keadaan semakin mendesak, tekanan di sana sini terhadap pengikutnya, Rasulullah memerintahkan agar kaumnya hijrah dan mendakwahkan Islam ke Habasyah. Rasulullah tahu bahwa raja yang berkuasa adalah seorang raja yang adil, tak bakal ada seorang pun yang teraniaya di sisinya. Pada bulan Rajab tahun kelima dari nubuwah, sekelompok sahabat hijrah yang pertama kali ke Habasyah, terdiri dari dua belas orang lakilaki dan empat orang wanita, yang dipimpin Utsman bin Affan. Karena siksaan dan penindasan yang ditimpakan orang-orang Quraisy semakin menjadi-jadi, Nabi SAW tidak melihat cara lain kecuali memerintahkan mereka untuk hijrah untuk kedua kalinya. Kali ini hijrah berjumlah delapan puluh tiga orang laki-laki dan delapan belas wanita Sementara itu, Rasulullah SAW tetap berada di Mekkah untuk terus mendakwahkan agama Allah buat penduduk Mekkah.

Banyak kejadian yang terjadi setelah Rasulullah menetapkan perintah kepada pengikutnya untuk hijrah ke Habasyah, mulai dari keislaman Umar bin Khattab dan Hamzah bin Abdul Muthalib, yang membuat Islam semakin kuat, hingga keadaan duka hati Rasulullah atas meninggalnya paman beliau Abu Thalib dan Istri beliau Khadijah binti Khuwailid terobati.

Pada tahun kesepuluh dari nubuwah, Rasulullah SAW pergi ke Thaif, beliau pergi dengan berjalan kaki. Dengan didampingi pembantunya Zaid bin Haritsah, beliau mengajak penduduk setiap kabilah yang ia lalui kepada Islam, namun tak satu pun yang memenuhinya. Sesampainya di Thaif, beliau menyeru agama Allah kepada pemimpin Bani Tsaqif. Namun semua menolaknya dan mencaci maki beliau sambil melempari batu kearah beliau. Pembantu Nabi SAW, Zaid senantiasa melindungi beliau. Saat musim haji tiba, beliau kembali ke Mekkah dan berdakwah kepada orang-orang yang melaksanakan haji dari segala penduduk di

\footnotetext{
${ }^{15}$ Ajid Thohir, Perkembangan peradaban di kawasan dunia Islam: melacak akar-akar sejarah, sosial, politik, dan budaya umat Islam, Cet. 1 (Jakarta: Divisi Buku Perguruan Tinggi, RajaGrafindo Persada, 2004), hal.13.
} 
luar Mekkah. Agama Allah mereka bawa ke negerinya, hingga tersebar luaslah Islam di Jazirah Arab. Di antaranya yaitu :

- Suwaid bin Shamit, seorang penyair yang cerdas dari penduduk Yatsrib, yang juga di juluki Al-Kamil oleh kaumnya.

- Iyas bin Mu'adz, seorang pemuda belia dari Yatsrib.

- Abu Dzarr Al-Ghifary, dia termasuk penduduk pinggiran Yatsrib.

- Thufail bin Amr Ad-Dausy, seorang Penyair cerdas dan pemimpin Kabilah Daus

- Dhimad Al-Azdy, berasal dari Azd Syanu'ah dari Yaman.

Dalam beberapa waktu, sampailah Islam ke penjuru Jazirah Arab, hingga ke Madinah, Islam di Madinah disambut baik oleh penduduknya. Dakwah Islam berhasil di bumi Yatsrib ini, yang membuat semua ketentuan Allah semakin bercahaya dan bersinar. Intisari dakwah Islam yang diberikan Nabi di Makkah selama lebih kurang 13 tahun meliputi i'tikad dan keimanan, amal ibadat, dan akhlak ${ }^{16}$. Rasulullah memberikan pendidikan dan pengajaran selama di Makkah ialah pendidikan keagamaan dan akhlak serta menganjurkan kepada manusia, supaya mempergunakan akal pikirannya memperhatikan kejadian manusia, hewan, tumbuh-tumbuhan dan alam semesta sebagai anjuran pendidikan 'akliyah dan ilmiyah ${ }^{17}$. Dakwah yang dilakukan oleh baginda rasul Saw adalah dakwah bil hikamh wal mauizah hasanah, dakwah yang jauh dari sikap kekekeran seperti mana yang banyak disah pahami orang tentang Islam dan yang menyebutkan bahwa ideologi agama menjadi faktor penyebab terorisme dan korelasinya yang kuat pada fundamentalisme agama ${ }^{18}$

\section{B. Pemikiran dan Peradaban Islam di Madinah}

Hijrah Rasulullah dan ummat Islam ke Madinah tidaklah terwujud begitu saja. Ada kondisi yang mendukung terjadinya hijrah tersebut, yaitu Bai at Aqabah (pertama dan kedua). Maksud penduduk Yastrib mengundang Rasulullah datang ke negerinya adalah guna mendamaikan pertikaian antar suku yang tidak kunjung berhenti. Dengan adanya Rasulullah

\footnotetext{
${ }^{16}$ Zubaidah, Sejarah Peradaban Islam, hal.20.

${ }^{17}$ Hamim Hafiddin, “Pendidikan Islam pada Masa Rasulullah” 1, no. 1 (2015): hal.21.

${ }^{18}$ Syaugi Mubarak, Badrian, dan Faisal Mubarak Seff, "PERAN KEARIFAN LOKAL DALAM UPAYA DERADIKALISASI FAHAM RADIKAL DI KALIMANTAN SELATAN," Khazanah: Jurnal Studi Islam dan Humaniora 2, no. 18 (2020): 122.
} 
diharapkan pertikaian itu dapat berhenti. Peta demografis Madinah saat itu adalah sebaagai berikut:

(1) Kaum Muslimin yang terdiri dari Muhajirin dan Anshar,

(2) Anggota suku Aus dan Khazraj yang masih berada pada tingkat nominal muslim, bahkan ada yang secara rahasia memusuhi Rasulullah,

(3) Anggota suku Aus dan Khazraj yang masih menganut paganisme,

(4) Orang-orang Yahudi yang terbagi dalam tiga suku utama: Banu Qainuqa, Banu Nadhir, dan Banu Quraizha. Kemajemukan komunitas tersebut tentu saja melahirkan conflict dan tension. Pertentangan Aus dan Khazraj sudah terlalu terkenal dalam sejarah Islam. Bahkan diduga diterimanya Rasulullah di Yastrib dengan baik di $17 \mathrm{kedua}$ klan tersebut karena kedua klan tersebut membutuhkan "orang ketiga" dalam konflik diantara mereka. Hal ini bisa dipahami dalam manajemen konflik politik. Adapun diterimanya Rasulullah oleh kaum Yahudi merupakan catatan tersendiri. Tentu saja Yahudi menerima Rasulullah dengan penuh kecurigaan tetapi pendekatan yang dilakukan Rasulullah mampu "menjinakkan" mereka, paling tidak, sampai Rasulullah eksis di Madinah ${ }^{19}$.

Dari sudut pandang ilmu politik, obyek yang dipimpin oleh Rasulullah.memenuhi syarat untuk disebut sebagai negara. Syarat berdirinya negara ialah ada wilayah, penduduk dan pemerintahan yang berdaulat. Kenyataan sejarah menunjukkan adanya elemen negara tersebut.Walhasil, setelah melalui proses Ba iat dan Piagam Madinah Nabi dipandang bukan saja sebagai pemimpin ruhani tetapi juga sebagai kepala negara. Kita beralih pada persoalan ajaran Islam. Pada periode Madinah ajaran Islam merupakan kelanjutan dari periode Mekkah. Bila pada periode Mekkah, ayat tentang hukum belum banyak diturunkan, maka pada periode Madinah kita mendapati ayat hukum mulai turun melengkapi ayat yang telah ada sebelumnya. Ini bisa dipahami mengingat hukum bisa dilaksanakan bila komunitas telah terbentuk. Juga dapat dicatat kemajemukan komunitas Madinah turut mempengaruhi ayat hukum ini. Satu contoh menarik pada peristiwa kewajiban zakat dan pelarangan riba. Setting sosio-ekonomi Madinah yang dikuasai oleh Yahudi memerlukan sebuah "perlawanan" dalam bentuk zakat (untuk pemerataan ekonomi di kalangan muslim) dan pelarangan riba. Yang terakhir ini membawa implikasi baik secara ekonomi maupun politik bagi praktek riba kaum Yahudi.

\footnotetext{
${ }^{19}$ Sari dan Hum, "SEJARAH PERADABAN ISLAM," hal.26.
} 
Bukan hanya ayat hukum saja yang berangsur-angsur "sempurna", juga ayat tentang etika, tauhid dan seluruh elemen ajaran Islam berangsur-angsur mendekati titik kesempurnaan,dan mencapai puncaknya pada QS 5:3. Setelah Nabi wafat, dimulailah era khulafaur rasyidin. Tidak dapat dipungkiri, di Madinah Islam sempurna dan disinilah awal sebuah peradaban yang dibangun oleh umat Islam mulai tercipta ${ }^{20}$.

Munculnya awal dari kenegaraan Islam di Madinah saat itu adalah dengan mendirikannya Rasulullah beberapa asas yang penting untuk daulah islamiyah pada saat itu diantaranya ada 3 asas yang dilaksanakan Rasulullah di periode Madinah:

-Asas pertama adalah pembangunan masjid

-Asas kedua adalah persaudaraan antara muslimin secara umum dan dari Muhajirin dan Anshar secara khusus

-Asas ketiga adalah penulisan dustur atau undang-undang yang disebut dengan Piagam Madinah yaitu sebagai peraturan kehidupan umat muslim di antara mereka dan memperjelas keterikatan mereka terhadap yang lainnya secara umum dan kaitannya orang muslim terhadap orang Yahudi secara khusus ${ }^{21}$.

Dalam asas pertama, Langkah pertama yang dilakukan Rasulullah SAW adalah membangun mesjid. Beliau terjun langsung dalam pembangunan mesjid itu, memindahkan

bata dan bebatuan. Mesjid itu bukan hanya merupakan tempat sholat semata, tapi juga merupakan sekolah bagi orang-orang Muslim untuk menerima pengajaran Islam dan bimbingan-bimbingannya, sebagai balai pertemuan dan tempat untuk mempersatukan berbagai unsur kekabilahan dan sisa-sisa pengaruh perselisihan semasa jahiliyah. Di samping semua itu, mesjid tersebut juga berfungsi sebagai tempat tinggal orang-orang Muhajirin yang miskin, yang datang ke Madinah tanpa memiliki harta, tidak punya kerabat dan masih bujangan atau belum berkeluarga ${ }^{22}$.

Pada asas kedua, Rasulullah SAW menjadikan asas persaudaraan yang terhimpun di dalamnya persatuan umat dan aqidah islamiyah yang datang kepada mereka dari Allah subhanahu wa ta'ala yang telah ditetapkan atas seluruh manusia menjadikan amal peribadatannya ikhlas karena Allah ta'ala tidak peruntukan kepada sesuatu yang bertentangan

\footnotetext{
${ }^{20}$ lbid, hal. 2 ㄱ.

${ }^{21}$ Albuthi, Fiqh al Siirah Muhammad SAW, hal.151.

${ }^{22}$ Zubaidah, Sejarah Peradaban Islam, hal.22.
} 
kecuali pada ketakwaan dan amal saleh. Menjadikan pada asas persaudaraan ini saling menolong dan tasamuh di antara satu dan yang lainnya tanpa ada keegoisan dalam aqidah mereka atau pemikiran-pemikiran yang berbeda, menjadikan asas berdirinya persaudaraan antara Muhajirin dan Anshar dalam keadilan persatuan yang dilaksanakannya menjadikan hakikat aqidah islamiyah dan dampak positif bagi lingkungan Islam $^{23}$.

Dan pada asas ketiga, Piagam Madinah ini menjadikan poin-poin secara menyeluruh yang jelas bagi peraturan kenegaraan dari dalam dan luar di Madinah, yaitu berkaitan perorangan ataupun suku dengan yang lainnya. Dan bahwa hukum keadilan yang ada pada piagam Madinah ini, sesuai dengan syariat Nya Allah dan hukumnya karena berpegang teguh dengan Al-Qur'an dan sunah Rasulullah. Dengan adanya piagam Madinah ini maka muncullah peradaban kenegaraan Madinah yang benar dan kuat asasnya ${ }^{24}$.

Dari sudut pandang ilmu politik, obyek yang dipimpin oleh Rasulullah.memenuhi syarat untuk disebut sebagai negara. Syarat berdirinya negara ialah ada wilayah, penduduk dan pemerintahan yang berdaulat. Kenyataan sejarah menunjukkan adanya elemen negara tersebut.Walhasil, setelah melalui proses Ba`iat dan Piagam Madinah Nabi dipandang bukan saja sebagai pemimpin ruhani tetapi juga sebagai kepala negara. Kita beralih pada persoalan ajaran Islam. Pada periode Madinah ajaran Islam merupakan kelanjutan dari periode Mekkah. Bila pada periode Mekkah, ayat tentang hukum belum banyak diturunkan, maka pada periode Madinah kita mendapati ayat hukum mulai turun melengkapi ayat yang telah ada sebelumnya. Ini bisa dipahami mengingat hukum bisa dilaksanakan bila komunitas telah terbentuk. Juga dapat dicatat kemajemukan komunitas Madinah turut mempengaruhi ayat hukum ini. Satu contoh menarik pada peristiwa kewajiban zakat dan pelarangan riba. Setting sosio-ekonomi Madinah yang dikuasai oleh Yahudi memerlukan sebuah "perlawanan" dalam bentuk zakat (untuk pemerataan ekonomi di kalangan muslim) dan pelarangan riba. Yang terakhir ini membawa implikasi baik secara ekonomi maupun politik bagi praktek riba kaum Yahudi.

Bukan hanya ayat hukum saja yang berangsur-angsur "sempurna", juga ayat tentang etika, tauhid dan seluruh elemen ajaran Islam berangsur-angsur mendekati titik kesempurnaan,dan mencapai puncaknya pada QS 5:3. Setelah Nabi wafat, dimulailah era khulafaur rasyidin.

\footnotetext{
${ }^{23}$ Albuthi, Fiqh al Siirah Muhammad SAW, hal.157.

${ }^{24}$ Ibid, $\underline{\text { hal. }}$ ․ㅡ․‥
} 
Tidak dapat dipungkiri, di Madinah Islam sempurna dan disinilah awal sebuah peradaban yang dibangun oleh umat Islam mulai tercipta ${ }^{25}$.

Pengajaran Rasulullah pada sekolah kehidupan yang luas tanpa di batasi dinding kelas. Dimanapun ada berbagai kesempatan yang mengandung nilai-nilai pendidikan dimanfaatkan sebagai sarana menyampaikan ajarannya dimana saja seperti di rumah, di masjid, di jalan, dan di tempat-tempat lainnya. Pokok pembinaan pendidikan Islam di kota Madinah dapat dikatakan sebagai pendidikan sosial dan politik. Yang merupakan kelanjutan dari pendidikan tauhid di Makkah, yaitu pembinaan di bidang pendidikan sosial dan politik agar dijiwai oleh ajaran, merupakan cermin dan pantulan sinar tauhid tersebut ${ }^{26}$.

Zulqarnaian mengutip bahwa Samsul Nizar menyebutkan Hasil pendidikan Islam periode Rasulullah terlihat dari kemampuan murid-muridnya (para sahabat) yang luar biasa. Misalnya Umar Bin Khattab ahli Hukum dan Pemerintahan, Abu Hurairah ahli Hadis, Salman al-Farisi ahli perbandingan agama (Majusi, Yahudi, Nasrani, dan Islam), dan Ali Ibn Abi Thalib ahi Hukum dan Tafsir al-Qur'an. Kemudian murid dari sahabat Rasulullah di kemudian hari, banyak yang menjadi ahli dalam berbagai bidang ilmu pengetahuan-sains, teknologi, astronomi, filsafat yang mengantarkan Islam ke pintu gerbang zaman keemasan terutama pada fase awal kekuasaan dinasti Abbasiyyah ${ }^{27}$.

\section{A. Kesimpulan}

Dakwah Rasulullah dari zaman sebelum beliau diutus sebagai nabi dan rasul sudah memberikan contoh untuk kita bahwa dari suri tauladan akhlak beliau patut untuk kita contoh dalam keseharian kita.

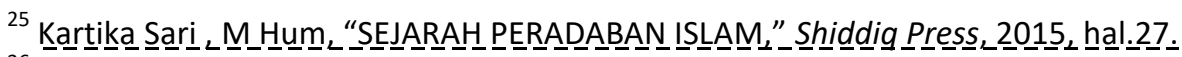

${ }^{26}$ Hafiddin, "Pendidikan Islam pada Masa Rasulullah," hal.24.

${ }^{27}$ Muh.Alif Kurniawan dkk., Sejarah Pemikiran dan Peradaban Islam: Dari Masa Klasik, Tengah, Hingga Modern (Qoulun Pustaka, 2014), hal.241.
} 
Seberat apapun yang Rasulullah hadapi Rasulullah selalu bergantung kepada Allah dengan segala susah payahnya cobaan yang Allah berikan beliau tetap berpegang teguh dengan ketauhidan dan menjunjung tinggi agama Islam yang beliau bawa.

Pada pada masa dakwah yang ada di Mekah Rasulullah bertitik fokus kepada penampakan agama Allah yakni Islam dan menyuruh kepada -Nya agar tidak ada lagi kebiasaan khurafat ataupun sembahan sembahan yang tidak semestinya untuk disembah, untuk menjunjung tinggi tauhidullah.

Dakwah Rasulullah secara sirriyah dan dan terang-terangan itu adalah tahapan bagaimana kita harus menjalani sesuatu itu secara alami pendekatan yang terdekat untuk didahulukan.

Intisari dakwah Islam yang diberikan Nabi di Makkah selama lebih kurang 13 tahun meliputi: i'tikad dan keimanan, amal ibadat, dan akhlak.

Lalu pada masa periode Madinah Rasulullah saat semakin membuat Islam kuat dengan para sahabat maka dimulailah titik untuk lebih memperluas penyebaran Islam. sejarah pemikiran dan peradaban dalam bidang ini sangat berpegang teguh dengan sumber ajaran Al-Qur'an dan Hadist, yang mana dari situ Islam datang membawa sistem sosial dan bilateral dalam kurun waktu 23 tahun selama Rasulullah diutus sampai akhir hayatnya.

Kiranya sampai disini, dari tulisan ini mungki banyak sekali kesalahan atau yang perlu dikoreksi lagi karna saya masih dalam proses belajar.Semoga membawa manfaat dan bisa mengamalkan bagaimana Rasulullah dalam pemikiran dan peradaban Islam di awal kejayaannya. Wallahu'alam bisshowaab.

\section{DAFTAR PUSTAKA}

Al-Qur'an dan Terjemahnya

Albuthi, Muhammad Sa'eed Ramadhan. Fiqh al Siirah Muhammad SAW. Beirut-Lebanon: Dar El Fikr, 1993.

Fu'ad, Zakki. Sejarah Peradaban Islam Paradigma Teks, Reflektif, dan Filosofis, t.t. Hafiddin, Hamim. "Pendidikan Islam pada Masa Rasulullah" 1, no. 1 (2015): 14.

Ibrahim, Qasim A, dan Muhammad A Saleh. Buku Pintar Sejarah Islam Jejak Langkah Peradaban Islam Dari Masa Nabi Hingga Masa Kini. Zaman, 2014. 
Kurniawan, Muh.Alif, Rochanah, Suyatmi, Ali fajar isbakhi, Kuni Adibah, Syifaun Nikmah, Ahmad Fathoni, dkk. Sejarah Pemikiran dan Peradaban Islam: Dari Masa Klasik, Tengah, Hingga Modern. Qoulun Pustaka, 2014.

Mubarak, Syaugi, Badrian, dan Faisal Mubarak Seff. "PERAN KEARIFAN LOKAL

DALAM UPAYA DERADIKALISASI FAHAM RADIKAL DI KALIMANTAN

SELATAN." Khazanah: Jurnal Studi Islam dan Humaniora 2, no. 18 (2020): 122.

Nasution, Syamruddin. Sejarah Peradaban Islam. Pekan Baru - Riau: Yayasan Pustaka Riau, 2013.

Sari, Kartika, dan M Hum. "SEJARAH PERADABAN ISLAM." Shiddiq Press, 2015, 144.

Thohir, Ajid. Perkembangan peradaban di kawasan dunia Islam: melacak akar-akar sejarah, sosial, politik, dan budaya umat Islam. Cet. 1. Jakarta: Divisi Buku Perguruan Tinggi, RajaGrafindo Persada, 2004.

Zubaidah, Siti. Sejarah Peradaban Islam. Perdana Mulya Sarana, 2016. 